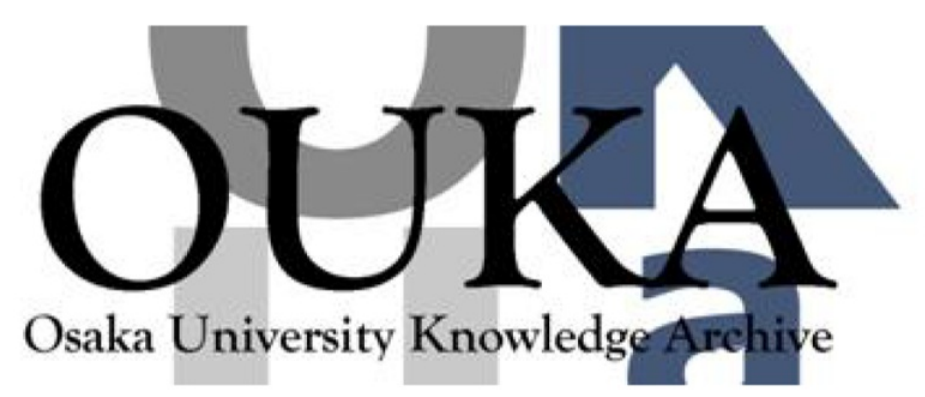

\begin{tabular}{|c|l|}
\hline Title & $\begin{array}{l}\text { Nickel phosphide nanoalloy catalyst for the } \\
\text { selective deoxygenation of sulfoxides to } \\
\text { sulfides under ambient } H_{2} \text { pressure }\end{array}$ \\
\hline Author(s) & $\begin{array}{l}\text { Fujita, Shu; Yamaguchi, Sho; Yamazoe, Seiji et } \\
\text { al. }\end{array}$ \\
\hline Citation & $\begin{array}{l}\text { Organic and Biomolecular Chemistry. 18(43) } \\
\text { p. 8827-p.8833 }\end{array}$ \\
\hline Issue Date & 2020-11-21 \\
\hline oaire:version & AM \\
\hline URL & https://hdl. handle.net/11094/78257 \\
\hline rights & \\
\hline Note & \\
\hline
\end{tabular}

Osaka University Knowledge Archive : OUKA

https://ir. Library. osaka-u. ac. jp/

Osaka University 


\title{
Nickel phosphide nanoalloy catalyst for the selective deoxygenation of sulfoxides to sulfides under ambient \\ $\mathrm{H}_{2}$ pressure
}

Shu Fujita, ${ }^{\mathrm{a}}$ Sho Yamaguchi, ${ }^{\mathrm{a}}$ Seiji Yamazoe, ${ }^{\mathrm{b}}$ Jun Yamasaki, ${ }^{\mathrm{c}}$ Tomoo Mizugaki ${ }^{\mathrm{a}}$ and Takato Mitsudome*a

a Department of Materials Engineering Science, Graduate School of Engineering Science, Osaka University, 1-3 Machikaneyama, Toyonaka, Osaka 560-8531, Japan

E-mail: mitsudom@cheng.es.osaka-u.ac.jp

b Department of Chemistry, Tokyo Metropolitan University, 1-1 Minami Osawa, Hachioji, Tokyo 1920397, Japan

c Research Center for Ultra-High Voltage Electron Microscopy, Osaka University, 7-1, Mihogaoka, Ibaraki, Osaka 567-0047, Japan

\begin{abstract}
Exploring novel catalysis by less common, metal-non-metal nanoalloys is of great interest in organic synthesis. We herein report a titanium-dioxide-supported nickel phosphide nanoalloy (nano$\mathrm{Ni}_{2} \mathrm{P} / \mathrm{TiO}_{2}$ ) that exhibits high catalytic activity for the deoxygenation of sulfoxides. nano- $\mathrm{Ni}_{2} \mathrm{P} / \mathrm{TiO}_{2}$ deoxygenated various sulfoxides to sulfides under 1 bar of $\mathrm{H}_{2}$, representing the first non-noble metal catalyst for sulfoxide deoxygenation under ambient $\mathrm{H}_{2}$ pressure. Spectroscopic analyses revealed that this high activity is due to cooperative catalysis by nano- $\mathrm{Ni}_{2} \mathrm{P}$ and $\mathrm{TiO}_{2}$.
\end{abstract}

KEYWORDS: nickel phosphide, heterogeneous catalyst, deoxygenation, sulfoxide, titanium dioxide

\section{Introduction}

It is well known that metal-metal nanoalloys often exhibit unique physicochemical properties that are superior to those of nanocrystals comprised of individual metals. ${ }^{1,2}$ In the field of catalysis, significant 
enhancements in activity, selectivity, and/or durability have been made by alloying two or more metals. ${ }^{3-5}$ In contrast, further extension beyond the use of traditional metal-metal nanoalloys to novel catalysis by metal-non-metal nanoalloys has not yet been widely explored. Recently, the rapid advance of nanoengineering technology has enabled the precise synthesis and catalytic application of metalnon-metal nanoalloys. Accordingly, metal-non-metal nanoalloys, e.g., metal phosphide nanoalloys, have been gaining attention as electrocatalysts for energy conversion reactions ${ }^{6-8}$ and petroleumreforming catalysts for hydrotreating reactions..$^{9-11}$ However, despite this catalytic potential, the catalytic applications of metal phosphide nanoalloys for the organic synthesis of fine and bulk chemicals are less developed. ${ }^{12-18}$ In this context, our research group has recently focused on exploring the novel catalysis by metal phosphide nanoalloys, finding that non-noble metal phosphide nanoalloy catalysts can outperform conventional metal nanoparticles for hydrogenation reactions. ${ }^{19,20}$ For instance, a nickel phosphide nanoalloy (nano- $\mathrm{Ni}_{2} \mathrm{P}$ ) represents the first example of a non-noble metal catalyst for the selective hydrogenation of biofuranic aldehydes to diketones in water. ${ }^{19}$ In addition, a cobalt phosphide nanoalloy (nano- $\mathrm{Co}_{2} \mathrm{P}$ ) exhibits outstanding catalytic performance for nitrile hydrogenation, with 20-500-fold greater activity than previously reported non-noble metal catalysts. ${ }^{20}$ Thus, catalysis by metal phosphide nanoalloys for liquid-phase molecular transformations represents an exciting research area that still has unexplored possibilities, especially for organic synthesis.

The deoxygenation of sulfoxides is an important transformation in organic synthesis because sulfoxides are utilized as chirons in asymmetric transformations. ${ }^{21-24} \mathrm{~A}$ target chiral compound can be synthesized through a series of reactions including the introduction of a chiral sulfoxide and its subsequent deoxygenation. To date, many stoichiometric methods using metal hydrides, ${ }^{25-27}$ hydrogen halides, ${ }^{28-30}$ thiols, ${ }^{31,32}$ and phosphines ${ }^{33-35}$ have been reported for the deoxygenation of sulfoxides. Alternative catalytic methods employing $\mathrm{Mo}, \mathrm{Re}, \mathrm{Cu}, \mathrm{Au}$, and $\mathrm{Ru}$ combined with phosphorus compounds, ${ }^{36-38}$ hydrosilanes, ${ }^{39-41} \mathrm{BH}_{3},{ }^{42-44}$ and alcohols ${ }^{45-47}$ have been also developed. However, these catalytic systems still suffer from low atom efficiency. In contrast, the catalytic deoxygenation of sulfoxides with $\mathrm{H}_{2}$ represents the most environmentally friendly method for the synthesis of sulfides with high atom efficiency because water is formed as the sole by-product. ${ }^{4-53}$ Our research group recently found that $\mathrm{Ru} / \mathrm{TiO}_{2}$ has a high catalytic activity for the deoxygenation of various sulfoxides under ambient $\mathrm{H}_{2}$ pressure. ${ }^{48}$ Subsequently, Pt- $\mathrm{MoO}_{\mathrm{x}} / \mathrm{TiO}_{2},{ }^{49} \mathrm{Pt} / \mathrm{V}_{0.7} \mathrm{Cr}_{0.3}-\mathrm{Hol},{ }^{50}$ and $\mathrm{Pt} / \mathrm{H}_{\mathrm{x}} \mathrm{MoO}_{3-\mathrm{y}}{ }^{51}$ catalysts were developed. As alternatives to expensive and rare noble-metal-based catalysts, low-cost and earth-abundant non-noble metal catalysts for the deoxygenation of sulfoxides have been also 
developed. In this context, only two non-precious metal catalysts have been reported for the deoxygenation of sulfoxides using $\mathrm{H}_{2} \cdot{ }^{52,53}$ One is a high-valent oxo-molybdenum(VI) complex catalyst which requires harsh reaction conditions (50 bar $\left.\mathrm{H}_{2}, 120{ }^{\circ} \mathrm{C}\right) .{ }^{52}$ The other is a Co-Mo/NC catalyst which operates well at room temperature but requires pressurized $\mathrm{H}_{2}$ (10 bar) and a long reaction time $(60 \mathrm{~h})$ to obtain sufficient sulfide yields. ${ }^{53}$ Therefore, the development of a new and efficient catalytic system based on a non-precious metal catalyst operating under mild conditions would greatly advance the utility of sulfoxide deoxygenation. Herein, we report that a titaniumdioxide-supported nickel phosphide nanoalloy (nano- $\mathrm{Ni}_{2} \mathrm{P} / \mathrm{TiO}_{2}$ ) exhibits high catalytic activity for the deoxygenation of sulfoxides to sulfides using $\mathrm{H}_{2}$ (Scheme 1). In contrast to the previously reported non-noble metal catalysts requiring high $\mathrm{H}_{2}$ pressures, nano- $\mathrm{Ni}_{2} \mathrm{P} / \mathrm{TiO}_{2}$ is the first example of a nonnoble metal catalyst that promotes the selective deoxygenation of various sulfoxides to the corresponding sulfides under ambient $\mathrm{H}_{2}$ pressure.

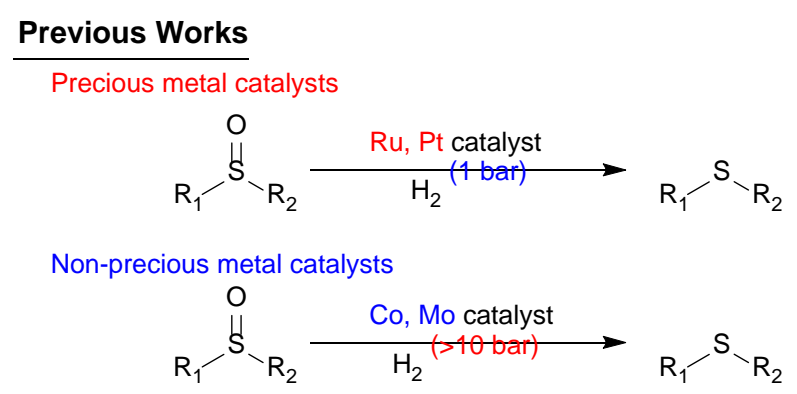

\section{This Work}

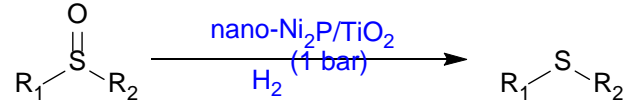

$$
\begin{aligned}
& \text { - Use of non-precious metal - Low pressure of } \mathrm{H}_{2} \text { (1bar) }
\end{aligned}
$$

Scheme 1 Catalytic deoxygenation of sulfoxides to sulfides using $\mathrm{H}_{2}$.

\section{Results and discussion}

nano- $\mathrm{Ni}_{2} \mathrm{P}$ was synthesized by a solvothermal method using nickel(II) chloride $\left(\mathrm{NiCl}_{2}\right)$ and triphenyl phosphite as the nickel and phosphorous precursors, respectively. ${ }^{19}$ For comparison, nano- $\mathrm{Co}_{2} \mathrm{P}$ and nano- $\mathrm{Fe}_{2} \mathrm{P}$ were prepared by similar methods (Fig. $\mathrm{S} 1$ and $\mathrm{S} 2$ ). The formation of nano- $\mathrm{Ni}_{2} \mathrm{P}$ was evidenced by X-ray diffraction (XRD). In the XRD pattern of nano-Ni ${ }_{2} \mathrm{P}$ (Fig. S1), the diffraction peaks located at $2 \theta=40.8^{\circ}, 44.7^{\circ}, 47.3^{\circ}$, and $54.1^{\circ}$ can be ascribed to the (111), (201), (210), and (300) planes of $\mathrm{Ni}_{2} \mathrm{P}$ (JCPDS card no. 03-0953), respectively. ${ }^{54}$ Fig. 1a shows a transmission electron 
microscopy (TEM) image of a collection of spherical nano- $\mathrm{Ni}_{2} \mathrm{P}$ particles, which have a mean diameter of $5.2 \mathrm{~nm}$. A high-magnification TEM image shows the well-resolved lattice fringes of nano- $\mathrm{Ni}_{2} \mathrm{P}$ (Fig. 1b), where the lattice spacings of 0.236 and $0.224 \mathrm{~nm}$ correspond to the (102) and (111) planes of hexagonal $\mathrm{Ni}_{2} \mathrm{P}$, respectively (Fig. 1c and $1 \mathrm{~d}$ ). ${ }^{55}$ Moreover, the selected area electron diffraction (SAED) pattern is consistent with that of hexagonal $\mathrm{Ni}_{2} \mathrm{P}$ (inset, Fig. $1 \mathrm{~b}$ ), which further verifies the formation of crystalline $\mathrm{Ni}_{2} \mathrm{P}^{56} \mathrm{Next}$, nano- $\mathrm{Ni}_{2} \mathrm{P}$ was immobilized on $\mathrm{TiO}_{2}$. nano- $\mathrm{Ni}_{2} \mathrm{P}$ was dispersed in hexane and then stirred with $\mathrm{TiO}_{2}$, giving nano- $\mathrm{Ni}_{2} \mathrm{P} / \mathrm{TiO}_{2}$. The high dispersion of nano- $\mathrm{Ni}_{2} \mathrm{P}$ on $\mathrm{TiO}_{2}$ was also confirmed, as depicted in Fig. 1e. These results clearly showed the successful immobilization of uniform and crystalline nano- $\mathrm{Ni}_{2} \mathrm{P}$ on $\mathrm{TiO}_{2}$.

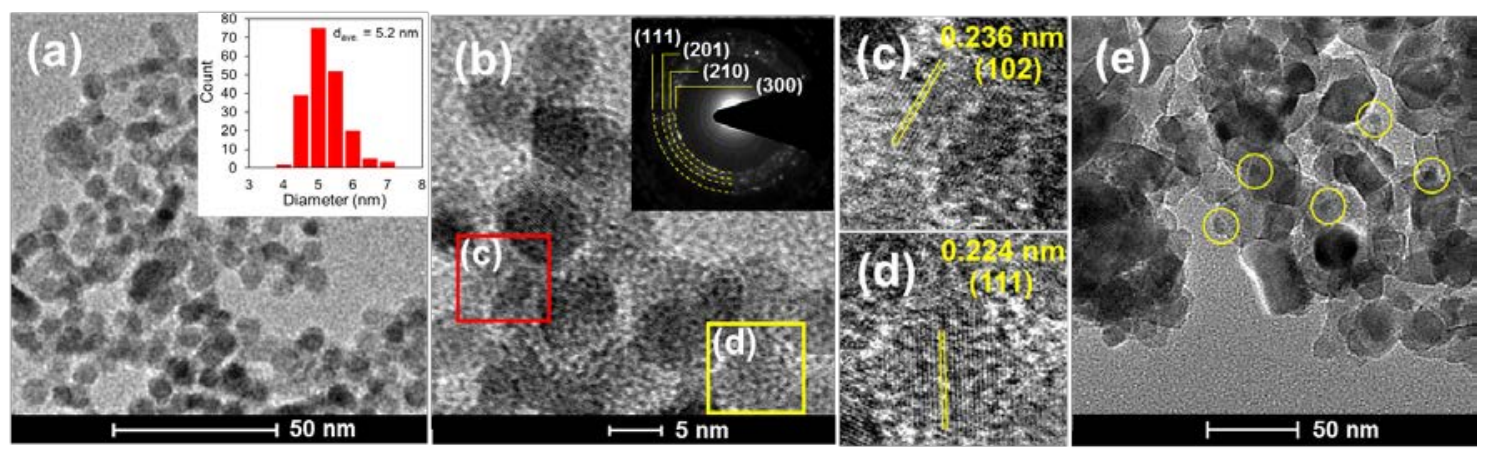

Fig. 1 a) TEM image and histogram of nano-Ni $i_{2} \mathrm{P}$. b) High-magnification TEM image of nano- $\mathrm{Ni}_{2} \mathrm{P}$ (the inset in (b) shows the corresponding SAED pattern). c) and d) Enlarged views of the area selected by the red and yellow square in (b), respectively. e) TEM image of nano- $\mathrm{Ni}_{2} \mathrm{P} / \mathrm{TiO}_{2}$ with nano- $\mathrm{Ni}_{2} \mathrm{P}$ marked in yellow circles.

We initially assessed the catalytic potential of various metal phosphide nanoalloys for the deoxygenation of diphenyl sulfoxide (1a) under 10 bar of $\mathrm{H}_{2}$ at $120^{\circ} \mathrm{C}$ for $1 \mathrm{~h}$, as summarized in Table 1. nano- $\mathrm{Ni}_{2} \mathrm{P}$ promoted the deoxygenation of $\mathbf{1 a}$, affording diphenyl sulfide (2a) in $14 \%$ yield (entry 1). In contrast, other non-noble metal phosphides, namely, nano- $\mathrm{Co}_{2} \mathrm{P}$, nano- $\mathrm{Fe}_{2} \mathrm{P}$, and bulk $\mathrm{Ni}_{2} \mathrm{P}$, showed almost no activity (entries $2-4$ ), revealing the unique deoxygenation catalysis by nano- $\mathrm{Ni}_{2} \mathrm{P}$. Next, active nano- $\mathrm{Ni}_{2} \mathrm{P}$ immobilized on various supports, such as $\mathrm{TiO}_{2}, \mathrm{ZrO}_{2}, \mathrm{Nb}_{2} \mathrm{O}_{5}, \mathrm{SiO}_{2}$, hydrotalcite (HT), and $\mathrm{Al}_{2} \mathrm{O}_{3}$, were tested for the deoxygenation of $\mathbf{1 a}$ (entries 5, 9-13). While most of the supported $\mathrm{Ni}_{2} \mathrm{P}$ alloys provided $\mathbf{2 a}$ in yields similar to or lower than that with unsupported nano$\mathrm{Ni}_{2} \mathrm{P}$, nano- $-\mathrm{Ni}_{2} \mathrm{P} / \mathrm{TiO}_{2}$ and nano- $\mathrm{Ni}_{2} \mathrm{P} / \mathrm{ZrO}_{2}$ had 2-3-fold higher activities, giving $2 \mathrm{a}$ in $33 \%$ and $28 \%$ yields, respectively (entries 5 and 9). These results showed that the combination of the $\mathrm{Ni}_{2} \mathrm{P}$ nanoalloy 
with $\mathrm{TiO}_{2}$ provides the best activity among the tested metal phosphide nanoalloy catalysts, suggesting that metal-support cooperation plays an important role in the present deoxygenation reaction. With

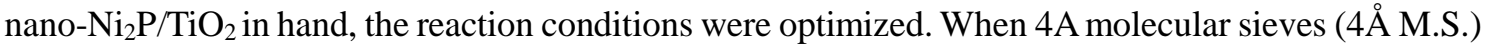
were added to remove the water generated during the reaction, the yield of $\mathbf{2 a}$ was further improved to $56 \%$ with a reaction time of $1 \mathrm{~h}$ and reached $98 \%$ when the reaction time was extended to $2.5 \mathrm{~h}$ (Table 1, entries 6 and 7). Notably, with nano- $\mathrm{Ni}_{2} \mathrm{P} / \mathrm{TiO}_{2}$, the reaction proceeded under just 1 bar of $\mathrm{H}_{2}$, providing 2a in 97\% yield (Table 1, entry 8). This is the first example of sulfoxide deoxygenation using a non-precious metal catalyst under ambient $\mathrm{H}_{2}$ pressure.

Next, we carried out a hot filtration experiment using nano- $\mathrm{Ni}_{2} \mathrm{P} / \mathrm{TiO}_{2}$ to confirm the occurrence of hydrogenation on the catalyst surface. After the removal of nano- $\mathrm{Ni}_{2} \mathrm{P} / \mathrm{TiO}_{2}$ by filtration at approximately 50\% conversion of 1a, no further conversion was observed (Fig. S3). In addition, the concentration of $\mathrm{Ni}$ in the filtrate was below the detection limit of inductively coupled plasma atomic emission spectrometry (ICP-AES), and the Ni loading amount of used nano- $\mathrm{Ni}_{2} \mathrm{P} / \mathrm{TiO}_{2}$ was almost the same as that of the fresh catalyst (Table S1). These results showed that nano- $\mathrm{Ni}_{2} \mathrm{P}$ was strongly immobilized on the $\mathrm{TiO}_{2}$ support and there was no leaching of Ni species from the catalyst, indicating that this is the active species for the deoxygenation of sulfoxides.

Table 1 Deoxygenation of diphenyl sulfoxide (1a) catalyzed by metal phosphide catalysts ${ }^{a}$<smiles>O=S(c1ccccc1)c1ccccc1</smiles>

$1 \mathrm{a}$

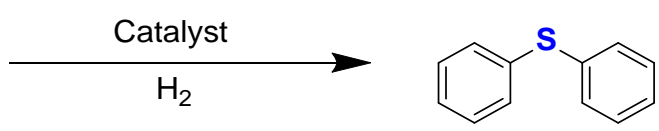

$2 a$

\begin{tabular}{llll}
\hline Entry & Catalyst & Time (h) & Yield (\%) \\
\hline 1 & nano- $\mathrm{Ni}_{2} \mathrm{P}$ & 1 & 14 \\
2 & nano-Co $2 \mathrm{P}$ & 1 & $<1$ \\
3 & nano- $\mathrm{Fe}_{2} \mathrm{P}$ & 1 & $<1$ \\
4 & bulk $\mathrm{Ni}_{2} \mathrm{P}$ & 1 & $<1$ \\
5 & nano- $\mathrm{Ni}_{2} \mathrm{P} / \mathrm{TiO}_{2}$ & 1 & 33 \\
$6^{c}$ & nano- $\mathrm{Ni}_{2} \mathrm{P} / \mathrm{TiO}_{2}$ & 1 & 56 \\
$7^{c}$ & nano- $\mathrm{Ni}_{2} \mathrm{P} / \mathrm{TiO}_{2}$ & 2.5 & 98 \\
$8^{d}$ & nano- $\mathrm{Ni}_{2} \mathrm{P} / \mathrm{TiO}_{2}$ & 12 & 97 \\
9 & nano- $\mathrm{Ni}_{2} \mathrm{P} / \mathrm{ZrO}_{2}$ & 1 & 28
\end{tabular}




\begin{tabular}{llll}
10 & nano- $\mathrm{Ni}_{2} \mathrm{P} / \mathrm{Nb}_{2} \mathrm{O}_{5}$ & 1 & 15 \\
11 & nano- $-\mathrm{Ni}_{2} \mathrm{P} / \mathrm{SiO}_{2}$ & 1 & 11 \\
12 & nano- $\mathrm{Ni}_{2} \mathrm{P} / \mathrm{HT}$ & 1 & 10 \\
13 & nano- $\mathrm{Ni}_{2} \mathrm{P} / \mathrm{Al}_{2} \mathrm{O}_{3}$ & 1 & 8 \\
\hline${ }^{a}$ Reaction conditions: catalyst (5 mol\% metal), 1a (0.5 mmol), toluene \\
$(3 \mathrm{~mL}), \mathrm{H}_{2}\left(10\right.$ bar), $120{ }^{\circ} \mathrm{C} .{ }^{b}$ Determined by gas chromatography-mass \\
spectrometry (GC-MS) using naphthalene as an internal standard. ${ }^{c} 4 \AA$ \\
M.S. (0.1 g). ${ }^{d} 4 \AA$ M.S. $\left(0.1\right.$ g), $\mathrm{H}_{2}$ (1 bar), $160{ }^{\circ} \mathrm{C}$.
\end{tabular}

The substrate scope of the sulfoxide deoxygenation reaction catalyzed by nano- $\mathrm{Ni}_{2} \mathrm{P} / \mathrm{TiO}_{2}$ under atmospheric $\mathrm{H}_{2}$ was investigated (Scheme 2). nano- $\mathrm{Ni}_{2} \mathrm{P} / \mathrm{TiO}_{2}$ efficiently promoted the selective deoxygenation of various sulfoxides, including aromatic (2a-2e) and aliphatic (2f-2i) substrates, giving the corresponding sulfides in high yields. Notably, functional groups such as halogens ( $2 \mathbf{j}$ and $2 \mathbf{k}$ ), ether (2l), carbonyls ( $2 \mathbf{m}$ and $2 \mathbf{n}$ ), and alkene (2o) were tolerated because nano- $\mathrm{Ni}_{2} \mathrm{P} / \mathrm{TiO}_{2}$ operated under mild conditions. In particular, selective deoxygenation of sulfoxide while retaining an aldehyde group was achieved for the first time, with nano- $\mathrm{Ni}_{2} \mathrm{P} / \mathrm{TiO}_{2}$ chemoselectively deoxygenating 4-(methylsulfinyl)benzaldehyde to the corresponding 4-(methylthio)benzaldehyde (2m). Furthermore, nano- $\mathrm{Ni}_{2} \mathrm{P} / \mathrm{TiO}_{2}$ was applicable to the gram-scale reaction: $1.0 \mathrm{~g}$ of $\mathbf{1 a}$ was successfully converted to 2a with a yield of 92\%, where a turnover number (TON) reached 92 (Scheme 3). This value of TON is significantly larger than those of previously reported non-noble metal catalyst systems (Table S3). This result demonstrates that the nano- $\mathrm{Ni}_{2} \mathrm{P} / \mathrm{TiO}_{2}$ shows high catalytic activity and durability for the deoxygenation of sulfoxides. Conclusively, the use of nano- $\mathrm{Ni}_{2} \mathrm{P} / \mathrm{TiO}_{2}$ provides a powerful method for the selective deoxygenation of various functionalized sulfoxides to the corresponding sulfides under ambient $\mathrm{H}_{2}$ conditions. 


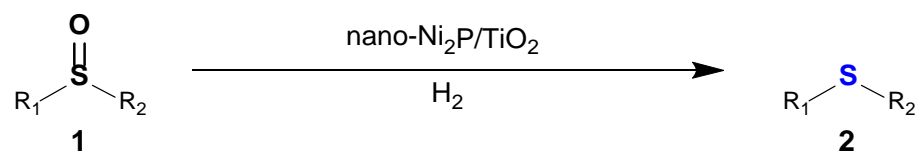

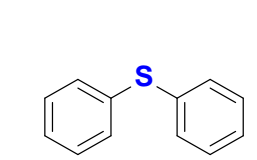

2a: $97 \%$

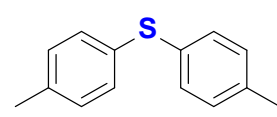

2b: $98 \%$

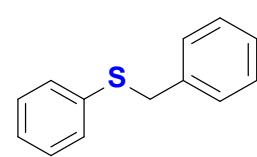

2c: $94 \%^{a}$

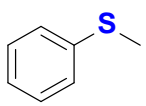

2d: $92 \% b$

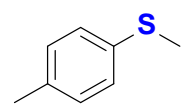

2e: $98 \% b$<smiles>CCCCSCCCC</smiles>

2f: $88 \%^{a}$

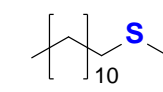

2g: $92 \%$

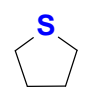

2h: $87 \%^{a}$

$$
\gamma^{\mathrm{S}} \mathrm{s}
$$

2i: $96 \%$

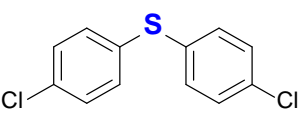

2j: 99\%<smiles>CSc1ccc(Br)cc1</smiles>

2k: $97 \% b$<smiles>COc1ccc(SC)cc1</smiles>

2l: $97 \%$<smiles>CSc1ccc(C=O)cc1</smiles>

2m: $97 \%^{c}$<smiles>CSc1ccc(CCSc2ccc(C(C)=O)cc2)cc1</smiles>

2n: $97 \%$

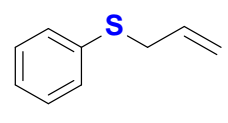

2o: $92 \%{ }^{c}$

Scheme 2 Deoxygenation of various sulfoxides catalyzed by nano- $\mathrm{Ni}_{2} \mathrm{P} / \mathrm{TiO}_{2}$. Reaction conditions:

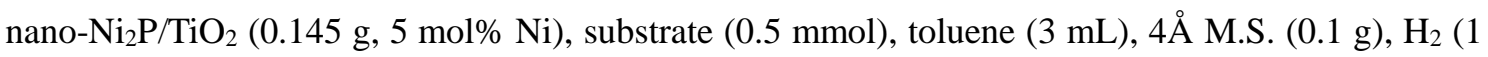
bar), $160{ }^{\circ} \mathrm{C}, 12 \mathrm{~h}$. Yields were determined by GC-MS using naphthalene as an internal standard. ${ }^{a} 10$ mol\% Ni, $140{ }^{\circ} \mathrm{C} .{ }^{b} 10 \mathrm{~mol} \% \mathrm{Ni} .{ }^{c} 10 \mathrm{~mol} \% \mathrm{Ni}, 120^{\circ} \mathrm{C}, 24 \mathrm{~h}$.<smiles>O=S(c1ccccc1)c1ccccc1</smiles>

$(1.0 \mathrm{~g})$

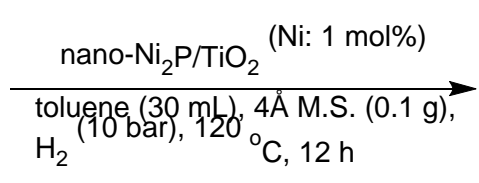
$\mathrm{H}_{2}{ }^{(10 \text { bar), }}, 12 \mathrm{O}^{\circ} \mathrm{C}, 12 \mathrm{~h}$<smiles>c1ccc(Sc2ccccc2)cc1</smiles>

$92 \%$ yield

Scheme 3 Gram-scale reaction of diphenyl sulfoxide using nano- $\mathrm{Ni}_{2} \mathrm{P} / \mathrm{TiO}_{2}$.

$\mathrm{X}$-ray absorption fine structure (XAFS) analysis was used to investigate the structure-activity relationship of nano- $\mathrm{Ni}_{2} \mathrm{P} / \mathrm{TiO}_{2}$. The X-ray absorption near-edge structure (XANES) spectra of Ni foil, $\mathrm{NiO}$, nano- $\mathrm{Ni}_{2} \mathrm{P}$, and nano- $\mathrm{Ni}_{2} \mathrm{P} / \mathrm{TiO}_{2}$ measured in air are shown in Fig. 2. The absorption edge energy of nano-Ni $2 \mathrm{P}$ (Fig. 2, red line) is close to that of $\mathrm{Ni}$ foil (Fig. 2, blue line), which indicates that the $\mathrm{Ni}$ species in nano- $\mathrm{Ni}_{2} \mathrm{P}$ are in a metallic state. ${ }^{19}$ Further, the absorption edge energy of nano- $\mathrm{Ni}_{2} \mathrm{P} / \mathrm{TiO}_{2}$ (Fig. 2, green line) is similar to that of nano- $\mathrm{Ni}_{2} \mathrm{P}$, suggesting that the $\mathrm{Ni}$ species in nano- $\mathrm{Ni}_{2} \mathrm{P}$ retain their metallic nature after immobilization on $\mathrm{TiO}_{2}$. However, slight changes in the spectral features of 
nano- $\mathrm{Ni}_{2} \mathrm{P} / \mathrm{TiO}_{2}$ suggest that $\mathrm{TiO}_{2}$ affects the local structure and/or electronic state of nano- $\mathrm{Ni}_{2} \mathrm{P}$. Hence, the nano- $\mathrm{Ni}_{2} \mathrm{P} / \mathrm{TiO}_{2}$ catalyst has an air-stable metallic nature that is active for hydrogenation, unlike conventional nickel(0) catalysts such as Raney $\mathrm{Ni}$ which are oxidatively degraded in the atmosphere. ${ }^{57}$ The Fourier transform of the extended XAFS (FT-EXAFS) spectrum of nano-Ni $2 \mathrm{P}$ showed two peaks at 1.7 and $2.3 \AA$, which are assigned to $\mathrm{Ni}-\mathrm{P}$ and $\mathrm{Ni}-\mathrm{Ni}$ bonds, respectively (Fig. S4). ${ }^{58,59}$ The absence of $\mathrm{Ni}-\mathrm{O}$ bonds indicated that nano- $\mathrm{Ni}_{2} \mathrm{P}$ is not oxidized, which is consistent with the XANES analysis. Curve-fitting analysis suggested that the Ni-Ni bond length of nano-Ni $2 \mathrm{P}(2.58$ $\AA$ ) was longer than that of $\mathrm{Ni}$ foil (2.48 $\AA$ ) owing to the formation of vertex-sharing $\mathrm{NiP}_{4}$ tetrahedra. Interestingly, nano- $\mathrm{Ni}_{2} \mathrm{P}$ was significantly different from bulk $\mathrm{Ni}_{2} \mathrm{P}$, in terms of the coordination number $(C N)$ ratio, with the $C N_{\mathrm{Ni}-\mathrm{Ni}} / C N_{\mathrm{Ni}-\mathrm{P}}$ ratio of nano- $\mathrm{Ni}_{2} \mathrm{P}(1.0)$ being smaller than the ideal value in bulk $\mathrm{Ni}_{2} \mathrm{P}$ (3.3) (Fig. S5 and Table S2). This small value for the $C N_{\mathrm{Ni}-\mathrm{Ni}} / C N_{\mathrm{Ni}-\mathrm{P}}$ ratio in nano-Ni $2 \mathrm{P}$ indicates the presence of highly coordinatively unsaturated $\mathrm{Ni}-\mathrm{Ni}$ sites on the surface which can activate $\mathrm{H}_{2} \cdot{ }^{14,19}$ The crystal structure of $\mathrm{Ni}_{2} \mathrm{P}$ and an exposed (300) plane are shown in Fig. S6. We infer that the lower $C N_{\mathrm{Ni}-\mathrm{Ni}} / C N_{\mathrm{Ni}-\mathrm{P}}$ ratio of nano- $\mathrm{Ni}_{2} \mathrm{P}$ is due to the exposure of the (300) plane because many $\mathrm{Ni}-\mathrm{Ni}$ sites are arranged on this plane. Hence, the difference between the deoxygenation activities of nano- $\mathrm{Ni}_{2} \mathrm{P}$ and bulk $\mathrm{Ni}_{2} \mathrm{P}$ is derived from the highly coordinatively unsaturated active sites for $\mathrm{H}_{2}$ on the exposed (300) plane of nano- $\mathrm{Ni}_{2} \mathrm{P}$.

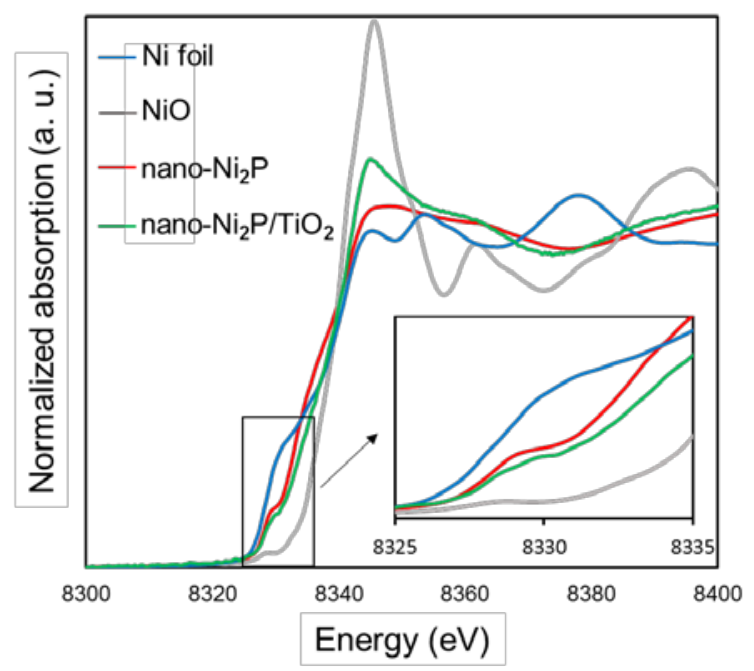

Fig. $2 \mathrm{Ni}$ K-edge XANES spectra of $\mathrm{Ni}$ foil, $\mathrm{NiO}$, nano- $\mathrm{Ni}_{2} \mathrm{P}$, and nano- $\mathrm{Ni}_{2} \mathrm{P} / \mathrm{TiO}_{2}$.

Next, X-ray photoelectron spectroscopy (XPS) measurements of nano- $\mathrm{Ni}_{2} \mathrm{P}$ were carried out. The 
Ni 2p XPS spectrum of nano- $\mathrm{Ni}_{2} \mathrm{P}$ showed two peaks located at 853.1 and $870.2 \mathrm{eV}$, which were similar to those of metallic Ni 2p $3 / 2(852.8 \mathrm{eV})$ and $\mathrm{Ni} 2 \mathrm{p}_{1 / 2}(870.0 \mathrm{eV})$ (Fig. S7), supporting the metallic nature of the Ni species in nano- $\mathrm{Ni}_{2} \mathrm{P}$. Furthermore, XPS measurements of nano- $\mathrm{Ni}_{2} \mathrm{P} / \mathrm{TiO}_{2}$ were performed to elucidate the role of $\mathrm{TiO}_{2}$ in the deoxygenation of sulfoxides. Fig. 3 shows the Ti 2p XPS spectrum of nano- $\mathrm{Ni}_{2} \mathrm{P} / \mathrm{TiO}_{2}$, where the Ti $2 \mathrm{p}_{3 / 2}$ peak located at $458.8 \mathrm{eV}$ corresponds to $\mathrm{Ti}^{4+}$ of $\mathrm{TiO}_{2}$ (Fig. 3a). After treating nano- $\mathrm{Ni}_{2} \mathrm{P} / \mathrm{TiO}_{2}$ under deoxygenation conditions without sulfoxides (10 bar $\mathrm{H}_{2}$ at $120^{\circ} \mathrm{C}$ for $1 \mathrm{~h}$ ), a peak assigned to $\mathrm{Ti}^{3+}$ appeared at $458.2 \mathrm{eV}$, suggesting that $\mathrm{Ti}^{4+}$ species on $\mathrm{TiO}_{2}$ is partially reduced to $\mathrm{Ti}^{3+}$ accompanied by the formation of oxygen vacancy $\left(\mathrm{O}_{\mathrm{v}}\right)$ sites (Fig. 3b). ${ }^{60,61}$ Furthermore, the $\mathrm{Ti}^{3+}$ peak disappeared by the subsequent treatment of nano- $\mathrm{Ni}_{2} \mathrm{P} / \mathrm{TiO}_{2}$ with 1a in toluene under an argon atmosphere (Fig. 3c), resulting in the production of 2a (Scheme S1). This result indicated that the in situ generated $\mathrm{Ti}^{3+}$ species are oxidized by sulfoxide, that is, the $\mathrm{O}_{\mathrm{v}}$ sites on $\mathrm{TiO}_{2}$ could deoxygenate $\mathbf{1 a}$ to $\mathbf{2 a}$.

Based on these results, we proposed a reaction pathway for the deoxygenation of sulfoxides catalyzed by nano- $\mathrm{Ni}_{2} \mathrm{P} / \mathrm{TiO}_{2}$ through the cooperative behavior of nano- $\mathrm{Ni}_{2} \mathrm{P}$ and $\mathrm{TiO}_{2}$ (Scheme 4). First, $\mathrm{H}_{2}$ is activated at a coordinatively unsaturated $\mathrm{Ni}-\mathrm{Ni}$ site on nano- $\mathrm{Ni}_{2} \mathrm{P}(\mathbf{I})$. Subsequently, the spillover hydrogen diffuses onto the $\mathrm{TiO}_{2}$ surface (II), where it reduces $\mathrm{TiO}_{2}$ to form an $\mathrm{O}_{\mathrm{v}}$ site (III). ${ }^{62,63}$ The $\mathrm{O}_{\mathrm{v}}$ site in $\mathrm{TiO}_{2}$ deoxygenates the sulfoxide to give a sulfide (IV), thereby completing the catalytic cycle. The cooperative effects of nano- $\mathrm{Ni}_{2} \mathrm{P}$ and $\mathrm{TiO}_{2}$ play key roles in the activation of $\mathrm{H}_{2}$ followed by the formation of $\mathrm{O}_{\mathrm{v}}$ sites and the deoxygenation of sulfoxide, respectively. This hybrid catalysis system leads to the high performance of nano- $\mathrm{Ni}_{2} \mathrm{P} / \mathrm{TiO}_{2}$ in the deoxygenation of sulfoxides.

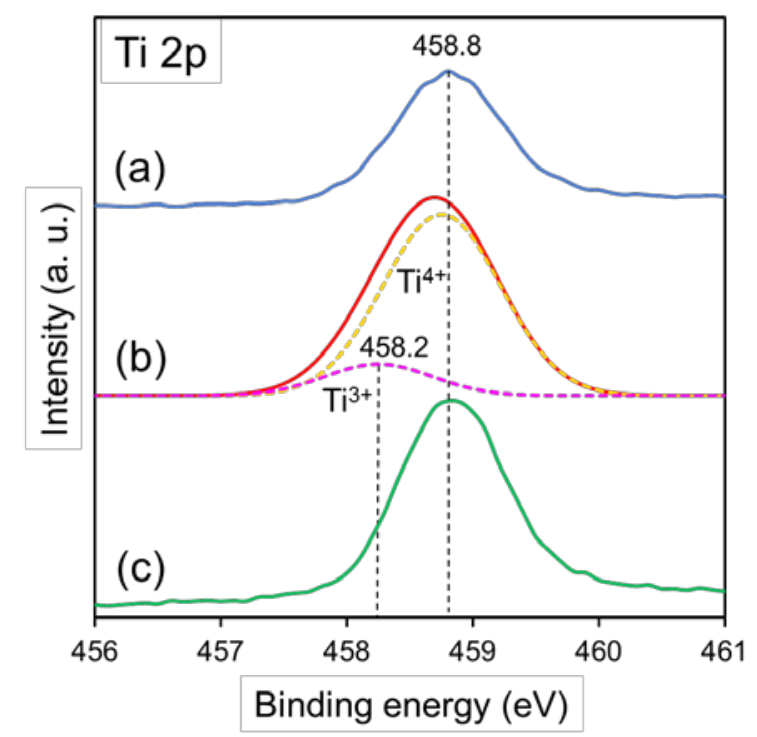


Fig. $3 \mathrm{Ti}$ 2p XPS spectra of a) nano- $\mathrm{Ni}_{2} \mathrm{P} / \mathrm{TiO}_{2}$, b) (a) after treatment with $\mathrm{H}_{2}$, and c) (b) after treatment with 1a. The curve-fitted data are shown as dash lines in (b).

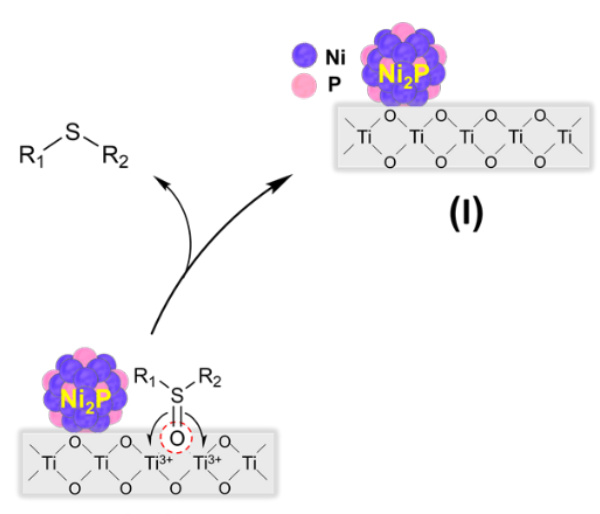

(IV)

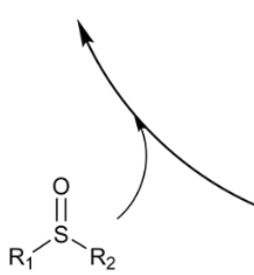

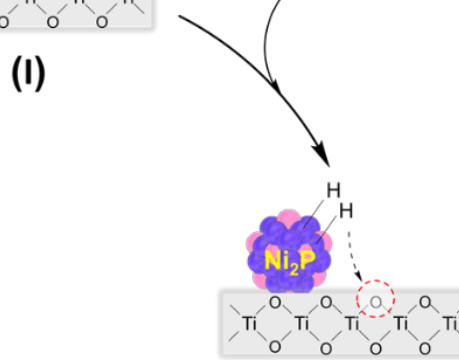

(II)

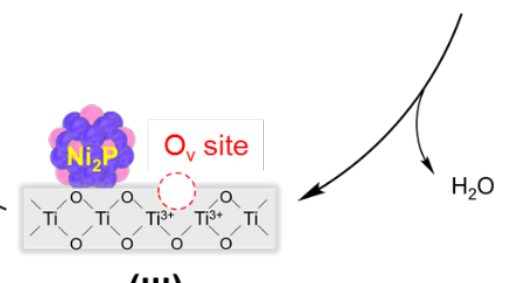

(III)

Scheme 4 Proposed reaction pathway for the deoxygenation of sulfoxides through the cooperative catalysis by nano- $\mathrm{Ni}_{2} \mathrm{P}$ and $\mathrm{TiO}_{2}$ support.

\section{Conclusion}

We found that a $\mathrm{TiO}_{2}$-supported $\mathrm{Ni}_{2} \mathrm{P}$ nanoalloy efficiently promoted the selective deoxygenation of sulfoxides to sulfides under mild conditions. This system is the first non-precious metal catalyst to achieve sulfoxide deoxygenation to sulfides under just 1 bar of $\mathrm{H}_{2}$. A wide variety of sulfoxides bearing reducible functional groups were chemoselectively converted to the corresponding sulfides in high yields while retaining the functional groups. XAFS and XPS analyses revealed that the $\mathrm{Ni}_{2} \mathrm{P}$ nanoalloy and $\mathrm{TiO}_{2}$ efficiently and cooperatively functioned to activate $\mathrm{H}_{2}$ and deoxygenate the sulfoxide, respectively, leading to high catalytic performance. These results confirm the potential of metal phosphide nanoalloys for catalysing a wide variety of molecular transformations under mild conditions. We envisage that our study will make a significant contribution to expand the unexplored catalytic potential of metal phosphide nanoalloys for organic synthesis.

\section{Experimental section}




\section{General information}

X-ray diffraction (XRD) studies were conducted on a Philips X'Pert-MPD diffractometer with Cu-Ko radiation. Transmission electron microscopy (TEM) was carried out FEI Tecnai G2 20ST instruments operating at $200 \mathrm{kV}$. Gas chromatography-mass spectrometry (GC-MS) was performed using a GCMS-QP2010 SE instrument equipped with an inert Cap WAX-HT capillary column (30 m × 0.25 $\mathrm{mm}$ i.d.). The oven temperature was programmed as follows: Starting temperature of $100^{\circ} \mathrm{C}$ held for $2 \mathrm{~min}$, then ramped to $280{ }^{\circ} \mathrm{C}$ at $20^{\circ} \mathrm{C} / \mathrm{min}$. Ni $\mathrm{K}$-edge X-ray absorption spectra were recorded at room temperature using a Si (111) monochromator at the BL01B1 line of SPring-8 at the Japan Synchrotron Radiation Research Institute (JASRI), Harima, Japan. The obtained spectra were analyzed using Athena software. After normalization at edge height, the $k^{3}$-weighted $\chi$ spectra were extracted. XPS analysis was performed on a KRATOS system equipped with a mono $\mathrm{Al}$ X-ray source and a hemispherical analyzer operating in the fixed analyzer transmission mode. The spectra were obtained at a pass energy of $40.0 \mathrm{eV}$ with an $\mathrm{Al}-\mathrm{K} \mathrm{X}$-ray source operating at $50 \mathrm{~W}$ and $154 \mathrm{kV}$. The analysis area was $0.7 \times 0.3 \mathrm{~mm}^{2}$ while the working pressure in the analysis chamber was less than $1 \times$ $10^{-8} \mathrm{~Pa}$. The $\mathrm{C} 1 \mathrm{~s}$ peak at a binding energy of $285.0 \mathrm{eV}$ was used as the internal reference.

\section{General procedure for the synthesis of nano- $\mathrm{Ni}_{2} \mathrm{P} / \mathrm{TiO}_{2}$}

All reactions were conducted under an argon atmosphere using standard Schlenk line techniques. In a typical synthesis, $\mathrm{NiCl}_{2} \cdot 6 \mathrm{H}_{2} \mathrm{O}(1.0 \mathrm{mmol})$ was combined with hexadecylamine $(10 \mathrm{mmol})$ and triphenyl phosphite $(10 \mathrm{mmol})$ in a Schlenk flask. The mixture was stirred at $120{ }^{\circ} \mathrm{C}$ for $1 \mathrm{~h}$. Subsequently, increasing the temperature to $315^{\circ} \mathrm{C}$ while stirring gave a black colloidal solution. The mixture was allowed to cool down to room temperature and the black product was then collected by centrifugation. The obtained powder was washed with a chloroform-acetone mixture (1:1, v/v) and dried in vacuo overnight to give nano- $\mathrm{Ni}_{2} \mathrm{P}$. Next, nano- $\mathrm{Ni}_{2} \mathrm{P}(22 \mathrm{mg})$ was dispersed in hexane (100 $\mathrm{mL}$ ) with sonication for $1 \mathrm{~h}$ and then stirred with $\mathrm{TiO}_{2}(1.0 \mathrm{~g})$ for $6 \mathrm{~h}$ at room temperature. The obtained powder was dried in vacuo overnight to give nano- $\mathrm{Ni}_{2} \mathrm{P} / \mathrm{TiO}_{2}$ as a grey powder. Similar procedures were used to prepare the other nano- $\mathrm{Ni}_{2} \mathrm{P} /$ support $\left(\mathrm{ZrO}_{2}, \mathrm{Nb}_{2} \mathrm{O}_{5}, \mathrm{SiO}_{2}, \mathrm{HT}\right.$, and $\left.\mathrm{Al}_{2} \mathrm{O}_{3}\right)$ catalysts.

\section{Typical catalytic reaction}

As a representative catalytic reaction, the transformation of $\mathbf{1 a}$ to $2 \mathbf{a}$ using nano- $\mathrm{Ni}_{2} \mathrm{P} / \mathrm{TiO}_{2}$ was typically performed as follows. First, nano- $\mathrm{Ni}_{2} \mathrm{P} / \mathrm{TiO}_{2}(0.145 \mathrm{~g})$ and $4 \AA$ M.S. (0.1 g) were placed in a $50 \mathrm{~mL}$ stainless-steel autoclave with a Teflon inner cylinder, followed by the addition of $\mathbf{1 a}(0.5 \mathrm{mmol})$ and toluene $(3 \mathrm{~mL})$. The reaction mixture was stirred vigorously at $120{ }^{\circ} \mathrm{C}$ under 10 bar of $\mathrm{H}_{2}$. The 
reaction solution was then analyzed by GC-MS to determine the conversion and yield using naphthalene as an internal standard method.

\section{Conflicts of interest}

The authors declare that they have no competing interests.

\section{Acknowledgments}

This work was supported by JSPS KAKENHI Grant Nos. 17H03456, 17H03457, 18H01790, and 20H02523. A part of this work was supported by the Cooperative Research Program of the Institute for Catalysis, Hokkaido University (20B1027) and the Nanotechnology Open Facilities in Osaka University (A-19-OS-0060), Ministry of Education, Culture, Sports, Science and Technology (MEXT), Japan. We thank Dr. Yoshikata Nakajima (Institute for NanoScience Design, Osaka University) for the TEM observation and Dr. Toshiaki Ina (SPring-8) for the XAFS measurements (2019A1390, 2019A1649, 2019B1560, and 2020A1487).

\section{Notes and references}

[1] K. D. Gilroy, A. Ruditskiy, H.-C. Peng, D. Qin and Y. Xia, Chem. Rev., 2016, 116, 10414-10472.

[2] M. Sankar, N. Dimitratos, P. J. Miedziak, P. P. Wells, C. J. Kiely and G. J. Hutchings, Chem. Soc. Rev., 2012, 41, 8099-8139.

[3] H. Fang, J. Yang, M. Wen and Q. Wu, Adv. Mater., 2018, 30, 1705698.

[4] W. Luo, M. Sankar, A. M. Beale, Q. He, C. J. Kiely, P. C. Bruijnincx and B. M. Weckhuysen, Nat. Commun., 2015, 6, 6540.

[5] L. Kesavan, R. Tiruvalam, M. H. Ab Rahim, M. I. bin Saiman, D. I. Enache, R. L. Jenkins, N. Dimitratos, J. A. Lopez-Sanchez, S. H. Taylor, D. W. Knight, C. J. Kiely and G. J. Hutchings, Science, 2011, 331, 195-199.

[6] Y. Li, Z. Dong and L. Jiao, Adv. Energy Mater., 2020, 10, 1902104.

[7] Y. Shi and B. Zhang, Chem. Soc. Rev., 2016, 45, 1529-1541.

[8] Y. Lv and X. Wang, Catal. Sci. Technol., 2017, 7, 3676-3691.

[9] M. C. Alvarez-Galvan, J. M. Campos-Martin and J. L. G. Fierro, Catalysts, 2019, 9, 293.

[10] S. T. Oyama, J. Catal., 2003, 216, 343-352.

[11] S. T. Oyama, T. Gott, H. Zhao and Y.-K. Lee, Catal. Today, 2009, 143, 94-107. 
[12] D. Albani, K. Karajovic, B. Tata, Q. Li, S. Mitchell, N. López and J. Pérez-Ramírez, ChemCatChem, 2019, 11, 457-464.

[13] Y. Zhu, S. Yang, C. Cao, W. Song and L.-J. Wan, Inorg. Chem. Front., 2018, 5, 1094-1099.

[14] R. Gao, L. Pan, H. Wang, X. Zhang, L. Wang and J.-J. Zou, ACS Catal., 2018, 8, 8420-8429.

[15] S. Yang, L. Peng, E. Oveisi, S. Bulut, D. T. Sun, M. Asgari, O. Trukhina and W. L. Queen, Chem. - Eur. J., 2018, 24, 4234-4238.

[16] J.-J. Shi, H.-J. Feng, C.-L. Qv, D. Zhao, S.-G. Hong and N. Zhang, Appl. Catal., A, 2018, 561, 127-136.

[17] Y. Chen, C. Li, J. Zhou, S. Zhang, D. Rao, S. He, M. Wei, D. G. Evans and X. Duan, ACS Catal., 2015, 5, 5756-5765.

[18] S. Carenco, A. Leyva-Pérez, P. Concepción, C. Boissière, N. Mézailles, C. Sanchez and A. Corma, Nano Today, 2012, 7, 21-28.

[19] S. Fujita, K. Nakajima, J. Yamasaki, T. Mizugaki, K. Jitsukawa and T. Mitsudome, ACS Catal., 2020, 10, 4261-4267.

[20] T. Mitsudome, M. Sheng, A. Nakata, J. Yamasaki, T. Mizugaki and K. Jitsukawa, Chem. Sci., 2020, 11, 6682-6689.

[21] S. C. A. Sousa and A. C. Fernandes, Coord. Chem. Rev., 2015, 284, 67-92.

[22] M. C. Carreño, Chem. Rev., 1995, 95, 1717-1760.

[23] M. Madesclaire, Tetrahedron, 1988, 44, 6537-6580.

[24] P. Bravo, G. Resnati, F. Viani and A. Arnone, Tetrahedron, 1987, 43, 4635-4647.

[25] J. Drabowicz and M. Mikołajczyk, Synthesis, 1976, 527-528.

[26] S. Kano, Y. Tanaka, E. Sugino and S. Hibino, Synthesis, 1980, 695-697.

[27] J. Zhang, X. Gao, C. Zhang, C. Zhang, J. Luan and D. Zhao, Synth. Commun., 2010, 40, 17941801.

[28] T. Aida, N. Furukawa and S. Oae, Tetrahedron Lett., 1973, 14, 3853-3856.

[29] D. Landini, A. M. Maia and F. Rolla, J. Chem. Soc., Perkin Trans. 2, 1976, 1288-1291.

[30] J. T. Doi and W. K. Musker, J. Am. Chem. Soc., 1981, 103, 1159-1163.

[31] T. J. Wallace and J. J. Mahon, J. Am. Chem. Soc., 1964, 86, 4099-4103.

[32] B. Karimi and D. Zareyee, Synthesis, 2003, 1875-1877.

[33] I. W. J. Still, S. K. Hasan and K. Turnbull, Can. J. Chem., 1978, 56, 1423-1428.

[34] S. Kikuchi, H. Konishi and Y. Hashimoto, Tetrahedron, 2005, 61, 3587-3591. 
[35] Y. Jang, K. T. Kim and H. B. Jeon, J. Org. Chem., 2013, 78, 6328-6331.

[36] Z. Zhu and J. H. Espenson, J. Mol. Catal. A, 1995, 103, 87-94.

[37] R. Sanz, J. Escribano, R. Aguado, M. R. Pedrosa and F. J. Arnáiz, Synthesis, 2004, 1629-1632.

[38] M. Bagherzadeh, M. M. Haghdoost, M. Amini and P. G. Derakhshandeh, Catal. Commun., 2012, 23, 14-19.

[39] S. C. A. Sousa, J. R. Bernardo, M. Wolff, B. Machura and A. C. Fernandes, Eur. J. Org. Chem., 2014, 1855-1859.

[40] S. Enthaler, ChemCatChem, 2011, 3, 666-670.

[41] Y. Mikami, A. Noujima, T. Mitsudome, T. Mizugaki, K. Jitsukawa and K. Kaneda, Chem. - Eur. J. 2011, 17, 1768-1772.

[42] A. C. Fernandes and C. C. Romão, Tetrahedron Lett., 2007, 48, 9176-9179.

[43] S. Enthaler, S. Krackl, E. Irran and S. Inoue, Catal. Lett., 2012, 142, 1003-1010.

[44] D. J. Harrison, N. C. Tam, C. M. Vogels, R. F. Langler, R. T. Baker, A. Decken and S. A. Westcott, Tetrahedron Lett., 2004, 45, 8493-8496.

[45] N. García, P. García-García, M. A. Fernández-Rodríguez, R. Rubio, M. R. Pedrosa, F. J. Arnáiz and R. Sanz, Adv. Synth. Catal., 2012, 354, 321-327.

[46] N. García, P. García-García, M. A. Fernández-Rodríguez, D. García, M. R. Pedrosa, F. J. Arnáiz and R. Sanz, Green Chem., 2013, 15, 999-1005.

[47] Y. Takahashi, T. Mitsudome, T. Mizugaki, K. Jitsukawa and K. Kaneda, Chem. Lett., 2014, 43, $420-422$.

[48] T. Mitsudome, Y. Takahashi, T. Mizugaki, K. Jitsukawa and K. Kaneda, Angew. Chem., Int. Ed., 2014, 53, 8348-8351.

[49] A. S. Touchy, S. M. A. H. Siddiki, W. Onodera, K. Kon and K. Shimizu, Green Chem., 2016, 18, 2554-2560.

[50] T. Uematsu, Y. Ogasawara, K. Suzuki, K. Yamaguchi and N. Mizuno, Catal. Sci. Technol., 2017, 7, 1912-1920.

[51] Y. Kuwahara, Y. Yoshimura, K. Haematsu and H. Yamashita, J. Am. Chem. Soc., 2018, 140, $9203-$ 9210.

[52] P. M. Reis, P. J. Costa, C. C. Romão, J. A. Fernandes, M. J. Calhorda and B. Royo, Dalton Trans., 2008, 1727-1733.

[53] K. Yao, Z. Yuan, S. Jin, Q. Chi, B. Liu, R. Huang and Z. Zhang, Green Chem., 2020, 22, 39-43. 
[54] Y. Feng, C. Xu, E. Hu, B. Xia, J. Ning, C. Zheng, Y. Zhong, Z. Zhang and Y. Hu, J. Mater. Chem. A, 2018, 6, 14103-14111.

[55] D. Yang, Y. Gu, X. Yu, Z. Lin, H. Xue and L. Feng, ChemElectroChem, 2018, 5, 659-664.

[56] Y. Ni, L. Jin and J. Hong, Nanoscale, 2011, 3, 196-200.

[57] D. Shi, R. Wojcieszak, S. Paul and E. Marceau, Catalysts, 2019, 9, 451.

[58] H. Zhao, S. T. Oyama, H.-J. Freund, R. Włodarczyk and M. Sierka, Appl. Catal., B, 2015, 164, 204-216.

[59] H.-R. Seo, K.-S. Cho and Y.-K. Lee, Mater. Sci. Eng., B, 2011, 176, 132-140.

[60] H. Huang, H. Huang, P. Hu, X. Ye and D. Y. C. Leung, Int. J. Photoenergy, 2013, 2013, 350570.

[61] P. Li, X. Guo, S. Wang, R. Zang, X. Li, Z. Man, P. Li, S. Liu, Y. Wu and G. Wang, J. Mater. Chem. A, 2019, 7, 2553-2559.

[62] M. Lu, Y. Sun, P. Zhang, J. Zhu, M. Li, Y. Shan, J. Shen and C. Song, Ind. Eng. Chem. Res., 2019, 58, 1513-1524.

[63] P. Zhang, Y. Sun, M. Lu, J. Zhu, M. Li, Y. Shan, J. Shen and C. Song, Energy Fuels, 2019, 33, 7696-7704. 